\title{
More Physicists than Jobs in the USA: A Lesson for Europe
}

During the past three years a serious manpower crisis in the hard sciences has developed in the USA, caused by a decrease in government funding of research together with the economic downturn. Although the resulting problems that confront the community of physicists in the States are probably not quite as severe as in other fields, such as chemistry, there is an imminent threat of the wreckage of careers which took many years and much money to build. Whole research programmes and entire laboratories are having to be closed down.

In Western Europe we are witnessing similar signs. It is now more difficult for Ph. D. physicists to find suitable positions than just a few years ago. While it is impossible to forecast to what extent we shall follow the American developments, proper and prompt attention should be paid in Europe to this new situation, and this ought to be one of the tasks of the European Physical Society.

The American situation concerns us not only indirectly. The lack of opportunities forces American physicists to look for employment, temporary or permanent, in Western Europe. Institute directors have noticed the sharply increased number of applications for positions from physicists in the United States. We may be witnessing the beginnings of a brain drain in reverse, at a rate comparable to that of the brain drain Europe suffered during the past decades.

This article aims to call attention to the developing crisis by analysing the situation in the USA on the basis of a recent report, "The Manpower Crisis in Physics", in the June 1971 Bulletin of the American Physical Society and prepared by L. Grodzins (MIT), Chairman of the Economics Concerns Committee of the American Physical So- ciety. The Committee, appointed in June 1970 , was "to examine what the American Physical Society can and should be doing to assist its members in the present situation and what implications this all has for long range policy on our profession ". One might well ask whether the EPS could not make a similar effort.

\section{A Sudden Crisis}

In 1967, the last of the 'fat' years in US physics, the turnover in $\mathrm{Ph}$. D. employment amounted to about $10 \%$ and the growth due to new $\mathrm{Ph}$. D. physicists to about $8 \%$, bringing their total to just over 20000 . The universities did not produce enough physicists to meet the demand, so that there was a net influx (160) of new $\mathrm{Ph}$. D.'s from abroad or from other disciplines, continuing a trend which had persisted since at least 1930. (It is estimated that from 1930 till now more than 5000 Ph. D.'s entered physics in the USA from other fields and from abroad.)

1968 saw the first decline in real money in the size of the government's research support, both for basic and applied physics; it has declined steadily since. The Report compares the 1967 employment situation with that of 1970 . The differences are dramatic: in 1970, a total of no more than 300 additional positions opened up in physics, of which 200 arose from death and retirement. At least 1000 fewer positions were available in 1970 than in 1967, whereas the graduating class in 1970 was $20 \%$ larger than in 1967. The situation has been much the same in industry: acquisition of new staff decreased by a factor of two between 1968 and 1970. Allowing for the turnover, there were about 2000 positions for $3000 \mathrm{Ph}$. D.'s. About 1100 of the new Ph. D.'s found acceptable positions, whereas 400 did not, and of the experienced Ph. D.'s, only 900 found acceptable new positions.

Thus, instead of a shortage of doctorates as in 1967 there was an excess of supply in 1970 almost equal to the production rate. This sudden crisis caused widespread disruption in careers and programmes. The Committee points out that the physicists being forced out of their profession are not part of the "losers of society' but are among the most talented of their generation. "If basic research does not return to a reasonable growth pattern soon we will have to contend with a wreckage of careers which took a decade and hundreds of thousands of dollars to build, in whole laboratories which took years to assemble, and in physics programmes vital to our future."

The manpower crisis in physics is not due to a disproportionate growth of Ph. D.'s in that field: over the past dozen years the production growth has been $9.5 \%$ per year, somewhat less than the $10.5 \%$ for all natural sciences, and not much larger than the $8 \%$ growth in the production of physicists from 1920 to 1942.

\section{Experience Does Not Pay}

The Report points out that in 1970 new Ph. D.'s fared somewhat better in finding positions than their more experienced colleagues. The new $\mathrm{Ph}$. D. has many advantages: he is mobile, works for less money and can be added as youngest member to an existing team. In most cases, his major professor, his department and his professional societies work to find him a post. The experienced $\mathrm{Ph}$. D. is in a much less favorable position. He may be one of the 2000 or so in the post- 
doctoral category (sometimes called the 'Invisible University ') with a high turnover (about $25 \%$ per year). What is important is that many in this category expect to have to find a new position within a few years and they are thus vulnerable to changes in the manpower situation. Otherwise he may be in a university post which ostensibly could lead to effective or actual tenure, but with the economic downturn and cuts in research funding many of these posts could not be renewed. As a result, many assistant professors and associate professors without tenure, as well as physicists in National Laboratories (Brookhaven, Oak Ridge, Argonne, etc.) had to look for new positions in 1970 .

In November of that year the American Institute of Physics (AIP) conducted a survey among experienced Ph.D.'s who had applied to the AIP Placement Service in 1970, mainly in the spring. Of the 202 who replied, only $60 \%$ reported that they were using their physics experience extensively, $32 \%$ definitely were not, and $7 \%$ were in positions classifiable as underemployed. Close to $40 \%$ of the experienced Ph.D.'s looking for new jobs in 1970 left the physics community.

\section{A Brain Drain in Reverse}

One result of the manpower crisis in the USA has been that more and more American physicists are looking for employment abroad. The report mentions that in $1970,14 \%$ of the physics graduates, half of them US citizens, left the country; of those, $55 \%$ went to Western Europe, two-thirds of these being Americans. Thus almost $6 \%$ of the US citizens who obtained their physics degrees in 1970 went to Europe for employment. Their number is close to 100 , an order of magnitude higher than in "normal" times. With an open European market for physicists, this would be no problem; on the contrary, Europe might recover some of the brain drain it suffered during the past decades. At present, however, the situation is quite different. Restrictive measures in research funding in most countries of Western Europe, following the American pattern, severely limit the possibilities of absorbing a surplus from across the Atlantic.

\section{The Outlook}

More important than the momentary crisis is the question regarding the dynamics of this process. The US Committee states that about $1500 \mathrm{Ph}$. D.'s have left the physics community in the USA. "The situation is deteriorating; the percentages going abroad, leaving physics, and of unemployed are all increasing. From an underproduction in 1967 we find ourselves with severe overproduction now. The abrupt reversal could not have been reasonably predicted and there are as many pitfalls to prophesying the future. We do not know what breakthroughs in fusion or in laser applications will require massive inputs of physicists. We cannot foretell whether disenchantment with science will grow or lessen. We do not yet know the commitment of the nation to the challenge of societal needs nor do we know the role of physics in meeting that commitment. We can, however, make several predictions which should be the basis for actions and planning.

First, in the next few years there will continue to be a severe imbalance between the training and the aspirations of students and the opportunities which will exist. The imbalance itself and the attendant problems could have been predicted. We should have known that in 1970 about $40 \%$ of the Ph.D. graduates would do their theses in either particle or nuclear physics. The subfield of elementary particle physics now contains about 1500 Ph.D. physicists; nuclear physics houses about 2000. Neither field has grown significantly in the past few years. Nuclear physics with its direct links to solid state physics, to medical physics, and to nuclear power provides greater options for its graduates but surely a $15 \%$ growth rate (half in theoretical aspects) is excessive. And we must realize that the many new nuclear accelerators in universities throughout the country will tend to maintain the outflow of students trained in nuclear physics.

Elementary particle physics is a field of zero population growth, at least for the near future. Yet the number of graduate students presently in the pipeline of particle physics (more than 1000 beyond their first year of graduate school) will sustain the output for years. At least $75 \%$, and probably more than $90 \%$, of this group will eventually have to find employment outside of elementary particle physics... Physics faculties now house $40 \%$ of the Ph.D. physicists. If the other sectors grow at the same rate as physics faculties, there will be a need for only 800 to 1200 new Ph.D.'s per year into the profession, which, with attrition, translates to a production need no greater than 1400 Ph.D.'s per year through the 1970's. Each reader can make his own reasonable estimates of the future needs for physicists... For many years, probably throughout this decade, ... the physics community will have to contend with an imbalance between training and aspirations, and the availability of matching jobs."

\section{Reducing the Pressure}

The APS Committee Report concludes with recommendations to alleviate the pressure building up on the job market for physicists. They are not long-range solutions; the actions are meant for the near future. Among these, we mention:

1. New opportunities must be found for physicists. Partial solutions can be effective, since the crisis involves a relatively small number of people. "For example, if each large hospital in the country were to employ one or two additional physicists (many hospitals already have physicists on their staff), if each large secondary school system were to employ a physicist as a science advisor..., if junior colleges were to realize the opportunity to obtain top-quality science teaching, if the promise of opportunities to work on societal needs becomes even a partial reality, if only some of each of 
these avenues are opened, then much of the immediate crisis will dissolve."

2. In the 1970's a larger share of the jobs for Ph.D. physicists must be found outside the educational institutions. Programmes to increase the physicists' involvement in industry need encouraging.

3. A National Placement Service based on field representatives working under a central body should be created.

4. Full information on the situation should be provided for students and faculties as quickly and as thoroughly as possible.

5. Physics departments should raise their standards for the Ph.D. They should establish whether "their students have the talent, the training and the attitudes for a physics career in a tightening market".

6. Training programmes for careers with few employment opportunities should be re-examined.

7. Reduce financial inducements which channel students into fields of little employment potential.

8. National fellowship programmes for students in science should be strongly supported.

9. "... In counselling students we gaze into the crystal ball to an uncertain time, years hence. There will be a need for physicists then as there has been in the past, but we cannot predict what fields or sub-fields will be fruitful... Apart from telling students the facts of the situation, we should advise them towards a well-grounded preparation in fundamentals, carried through with the broadest of attitudes and the widest of visions. We expect that a physics training based on such a foundation, however narrow may be the thesis topic, will better prepare a man for a future scientific career than would any alternative training."

The Report from which we have quoted so extensively indicates that the manpower situation for physicists in the US can only be described as grim. In all probability, the situation would be much more critical if the same were to happen in Europe. On the whole, the American physicist is characterized by great vitality and high mobility ; living in an economic system of fierce competition he generally does not hesitate to move, say, from Maine to California if job opportunities are better across the country. $\mathrm{He}$ is, on average, more polarized towards a problem-solving interpretation of his work as a physicist than his European colleague. These aspects will prove helpful in alleviating the present crisis.

\section{The New Role of Physics}

There is a wholesome effort to reassess the role of physics in the cultural pattern of our times. Efforts are made to communicate more effectively with the lay-public to tell "what physics is about". To illustrate this changed attitude, we quote from an article in the Chicago Tribune Magazine of 6 June 1971 on the new National Accelerator Laboratory near Batavia (about $50 \mathrm{~km}$ west of Chicago): "Physicists have usually regarded themselves as the aristocrats of science. The national frenzy to snare the accelerator lab of five years ago reinforced that belief... then. The goal of their science, after all, was to explain everything in the universe. Their gods were the best gods - Newton, Oppenheimer, Einstein, Fermi (whose name will become the official name of the laboratory when it is formally opened). And their post-World War II activities had significant effects not only on world science but also on United States politics... Physicists (as well as other scientists and engineers) have watched in horror as non-scientists - politicians - have calmly lopped off their financial heads, curtailing their research projects, shutting down their experimental installations. The public barely noticed. Wilson's Batavia laboratory is one of the survivors, and even its growth has been retarded.
Some of the physicists seem to have undergone mild personality changes as a result. The old loftiness is being held in, and the sense of patience and wanting to communicate more with non-physicists is being let out. It must be hard for them, but it doesn't stop them from trying. Those at Batavia will hold still for hours while a layman picks their brains about their arcane calling and peppers them with questions foolish enough to have made them redfaced with anger a few years ago." In the same article, there is an attempt to explain how the Batavia accelerator works in a popularized version, starring "Perry the Proton" and co-starring "Eddie Electron", "Norton Neutron", "Nicolo Neutrino" and "Molly Meson".

In addition, scientists are turning inward on their profession. In a speech prepared for the December 1970 meeting of the American Association for the Advancement of Science in Chicago, its president Glenn T. Seaborg said: "We in the scientific community would also do well to revitalize the notion of the wonder and beauty of science - for science is an emotional as well as an intellectual endeavour - and to stress the excitement of unravelling the mysteries of nature and the challenge of working with its forces to better the condition of man and his planet." In the same vein, Robert Wilson, Director of the Batavia Laboratory, describes the spirit of physics in the already quoted article in the Chicago Tribune Magazine: "Physics is a reflection of the same craving to explore that drove the Phoenicians, the Westward-Ho Americans, the moon astronauts, the 1971 hitchhikers and crawling babies...".

We, in Europe, watch the American scene with concern but not despondency. In the meantime, we must do everything in our power to ensure that the European physics community is prepared for the new situation.

L. Jansen 